\title{
Ulceras do estomago e do duodeno
}

Na sessão de 16 de agosto da Sociedade de Medicina e Cirurgia, o prof. Benedicto Montenegro apresentou uma serie de casos de gastro-duodenectomias parciaes que operou, tirando, do estudo minucioso delles, interessantes e muito bem documentadas condlusões. Larga discussão se fez em torno das palavras com que o prof. Montenegro relatou os seus casos, tomando parte nella o prof. Ovidio Pires de Campos e o $d r$. Octavio de Carvalho. A's objecções formuladas por esses illustres membros daquella sociedade, respondeu brilhantemente o prof. Benedicto Montenegro. Dada a importancia do assumpto e o interesse que a discussão despertou na classe medica paulista, transcrevemos abaixo a resposta do prof. Montenegro aos prof. Ovidio Pires de Campos e dr. Octavio de Carvalho, proferida no dia $1 .^{\circ}$ de setembro em sessão da mesma sociedade.

Q UANDO, em 16 do mez findo, eu trouxe a esta sociedade, uma communicação, que julguei interessante, sobre casos de ulceras gastricas e duodenaes por mim operados e curados pelo processo da gastro-duodenectomia parcial, procurei antes de tudo estabelecer esta preliminar: que trazia ao conhecimento dos illustres collegas que me ouviam, o meu contingente, a minha experiencia pessoal em assumpto tão vasto e de tamanha importancia.

Não desejava discutir os methodos e processos de outros que se occuparam desta materia e muito menos estabelecer o cotejo entre os seus resultados e os meus. O que eu visava, era, simples e unicamente, augmentar com o meu trabalho a litteratura já vastissima de tão interessante problema da pathologia gastro-intestinal, tão vasta, que eu me permitti, na occasião, a liberdade de repetir mutatis-mutandi as palavras do eminente prof. Mingazzini, proferidas em sua primeira conferencia sobre: "O cerebro e suas relações psychicas": "ella é tão grande, que toda uma existencia humana que só se occupasse de sua leitura, mal chegaria a esgotal-a" 
Os casos que eu trouxe á consideração dos meus illustres consocios, foram todos estudados por mim, auxiliado por meus dedicados assistentes. Procurei reunir todos os documentos para provar o que expuz e nisto tive que dispender um esfôrço e uma paciencia que só mesmo o muito amor pela verdade poderia levar-me a tanto. Bem sei quão imperfeito foi o meu trabalho, mas nem por isso me envergonho de o ter assim apresentado. Dadas as difficuldades que existem em nosso meio para se obter exames complementares completos de doentes particulares que não disponham de grandes recursos pecuniarios, eu estou convencido que fiz o que era possivel fazer. Expuz os meus casos com toda a franqueza, com toda sinceridade, com toda a lealdade e com o unico fim de trazer ao conhecimento dos collegas, o trabalho que vimos realisando, os meus assistentes e eu, em tão interessante quão complexo assumpto, sem "parti-pris" sem visar uma critica a quem quer que seja, mas, com o intuito unico de trazer aqui uma modestissima contribuição, fructo da minha experiencia e da minha meditação. Não tive a intenção de salientar erros e menos ainda de diminuir o valor de quem quer que seja. Trouxe ao conhecimento dos collegas factos que eu observei e que aqui demonstrei documentando-os com todas as provas. Não importa que os factos viessem demonstrar insuccessos de alguem: isto é tão banal que nem deveria merecer a attenção de um commentario.

Todos nós erramos, e muitas vezes; por isso, nenhum desdouro ha em confessarmos os nossos erros.

Em magistral conferencia realisada ha alguns annos aqui em S. Paulo pelo maior dos medicos brasileiros vivos, o prof. Miguel Couto, confessou elle, naquella occasião, que errava seguramente $20 \%$ dos seus diagnosticos e aprendia mais, dizia elle, quando errava pois que adquiria novo cabedal, do que quando acertava, pois ficava no que estava.

Ora, se isto acontece ao principe dos medicos brasileiros, o que não acontecerá a nós pobres ignorantes que ainda não conseguimos attingir o gráo de perfeição do veneravel mestre!

Dentro dos meus casos quiz eu me collocar e dentro da minha exposição pretendia eu que fosse o assumpto discutido.

Não pensaram assim os illustres collegas que se dignaram fazer reparos á minha communicação, o prof. Ovidio Pires de Campos e o dr. Octavio de Carvalho.

Ambos encaminharam a discussão para um terreno muito mais geral, justamente o que eu pretendia evitar, criticando as minhas affirmativas, não em face dos meus casos, mas em face do que ha escripto sobre tão magno assumpto, especialmente pelos autores extrangeiros, pois só elles foram citados pelos referidos collegas.

Sou, portanto, obrigado a declarar mais uma vez, que o que disse na sessão de 16 de Agosto, referia-se aos meus casos, mas, nem por isso, estou isolado nas minhas asserções e especialmente naquel- 
las que soffreram critica mais severa por parte dos meus collegas. Pelo contrario, as minhas palavras são o reflexo do pensamento de todos os eminentes mestres que trataram do assumpto e a esse respeito, sinto-me bem á vontade para affirmar que a minha observação concorda em linhas geraes e em muitas particulares com a observação dos mais abalisados autores.

Senão, vejamos: o prof. Ovidio Pires de Campo, secundado pelo dr. Octavio de Carvalho, não concordou commigo quando affirmei que o symptoma principal, o symptoma magno, o symptoma, por assim dizer da ulcera do estomago e principalmente da do duodeno é a dôr.

O dr. Octavio de Carvalho chegou mesmo a attribuir a Moynihan a affirmação de que este symptoma só se acha presente em 78 á $80 \%$ dos casos.

Nos meus casos elle é o symptoma principal, o mais constante por não ter faltado em nenhum delles, sob uma ou outra de suas modalidades, ao passo que os outros mostraram-se irregulares faltando neste ou naquelle doente.

Por ser o mais desconcertante para a vida do paciente, foi este symptoma que o levou a procurar um medico; foi elle que fez este medico suspeitar da presença de uma lesão necessitando de uma radio-graphia para seu esclarecimento, portanto, foi elle que levou o doente aos raios $\mathrm{X}$ e finalmente, foi elle, que não sendo debellado nem pelo tratamento medico e nem pela radio-therapia, levou o doente á mesa de operação:

E' o symptoma mais importante não só porque indica ao medico a conducta que deve ter em relação ao diagnostico da lesão que o provoca, como porque é em torno delle que gyra toda a therapeutica medica sob a pretensão de debellar a sua causa.

Foi, em meus casos, o symptoma principal da molestia, tanto assim que os meus doentes ao serem interrogados sobre o mal que os affligia, responderam sempre: - dôr de estomago e depois de uma pausa ou mesmo só depois de nova pergunta é que proseguiam na descripção dos outros symptomas.

Mas, se a minha experiencia com este importantissimo symptoma foi esta, eu não estou isolado no mundo, ao contrario, acho-me em muito boa companhia e já que os collegas quando discutiram a minha communicação invocaram o testemunho alheio, em seu favor, eu tambem me julgo com o direito de utilisal-o para corroborar as minhas affirmativas.

A respeito da dôr, assim se exprime o eminente cirurgião irlandez de Leeds, Sir Berkeley Moynihan, em suas duas licções sobre ulceras gastricas e duodenaes, á pag. 6 da edição franceza, traduzida pelo não menos eminente cirurgião francez, Victor Pauchet e publicada em 1924: - "Os symptomas classicos de uma ulcera são: as dôres, os vomitos e as hematemeses e entre estes, o unico que tem 
grande valor é a dôr" Eis aqui, como um cirurgião dos de maior, senão o de maior experiencia no assumpto, um dos que mais tem feito, já pelas suas operações, já pelas suas licções, já pelos seus escriptos, para esclarecer este vastissimo capitulo da pathologia do apparelho digestivo, um cirurgião de fama mundial colloca a dôr acima de todos os outros symptomas nas ulceras gastricas e duodenaes.

Eu não poderia achar melhor padrinho do que Moynihan, nome por todos respeitado e por isso eu sinto-me perfeitamente á vontade e com bastante coragem para continuar a minha affirmação de que a dôr occupa o $1 .^{\circ}$ logar e bem distanciada dos outros symptomas, na symptomatologia das ulceras gastricas e duodenaes.

Todavia, para não ser exclusivista e para satisfazer aos muito religiosos que só acreditam no baptismo depois de confirmado pela crisma, vou-me crismar convidando para meu padrinho o Martinet que diz o seguinte no fim da pag. 58 da $5 .^{a}$ edição do seu livro Diagnostic Clinique: "Em resumo, o diagnostico clinico da ulcera duodeno-pylorica nos parece poder ser feito nos doentes portadores de dôres do estomago, tendo os tres caracteres seguintes:

1. ${ }^{\circ}$ - Dôres sobrevindo em crises com intervallos de cura apparente.

$2 .^{\circ}$ - Dôres apparecendo algumas horas depbis da refeição.

3..$^{\circ}$ - Dôres apparecendo depois da ingestão de meio litro de leite e desaparecendo bruscamente depois de uma eructação."

Ora, aqui temos um autor dos mais acatados da França que affirma ser possivel o diagnostico de uma ulcera duodeno-pylorica, só pelo symptoma dôr! E note-se que Martinet não dispensa em seu livro, de uma descripção bem minuciosa e detalhada dos meios de pesquiza para se chegar ao diagnostico de uma ulcera.

Outro autor francez de grande nomeada, prof. da Faculdade de Medicina de Paris, Marcel Labbé, escrevendo no tomo VI, da collecção de Precis Medicaux, dedicado ás molestias do apparelho digestivo e da nutrição, diz, á pag. 217: "Dois grandes symptomas caracterisam a ulcera do estomago: a dôr e a gastrorrhagia." Dois grandes symptomas, diz o grande mestre francez, mas a dôr elle colloca em $1 .^{\circ}$ logar!

Ainda a pag. 220 do mesmo livro, em relação ao diagnostico da ulcera, le-se isto: "Nada mais facil do que o diagnostico dos casos typicos, nos quaes, ás dôres, juntam-se as hematemeses e a hyperchlorhydria num individuo jovem."

E' bem de notar-se que, ás dôres já existentes vêm-se juntar as hematemeses e a hyperchlorhydria para completar o caso clinico.

Eu me sinto tão bem e tão de accôrdo com os autores francezes que collocam a dôr em $10^{\circ}$ logar na symptomatologia das ulceras gastricas e duodenaes, que não posso deixar de citar mais algumas opiniões de filhos de nossa mãe espiritual. 
Lenoir e Agasse-Lafont, escrevendo sobre ulceras do estomago (Cruveilhier) na 2. ${ }^{\mathrm{a}}$ edição, no XIII vol. do Nouveau Traité de Medicine, publicado sob a direç̧ão dos profs. Roger, Widal e Teissier, assim se exprimem á pag. 548: "Signaes funccionaes. As perturbações do funccionamento do estomago nos doentes portadores de ulcera gastrica, manifestam-se por dôres que elles sentem durante as suas digestões e pela intolerancia gastrica com vomitos espontaneos ou provocados."

Mais abaixo: "Dôres - Um estomago são, deve funccionar sem que o individuo experimente ao seu nivel qualquer sensação desagradavel. Pelo contrario, o doente de ulcera queixa-se de phenomenos mais ou menos dolorosos que estão nitidamente em relação com a refeição, como o demonstra um interrogatorio methodico e preciso." Um interrogatorio methodico e preciso! Eis aqui um detalhe de grande importancia para a obtenção de dados que venham positivar o diagnostico de ulcera. Todo o tempo e paciencia são poucos para se alcançar tal desideratum!

G. Hayem e G. Lyon, no XVI vol. do Nouveau Traité de Medicine publicado em 1913, sob a direç̧ão dos profs. Gilbert e Thoinot, referindo-se á symptomatologia da ulcera do estomago, assim escrevem á pag. 344: “O desenvolvimento da ulcera é ás vezes, muito insidioso. Bruscamente, no meio de uma saude em apparencia perfeita, sobrevem, seja uma hematemese grave, sufficiente para provocar uma syncope ou mesmo a morte, seja uma peritonite aguda por perfuração. A bem dizer, si se procura no passado dos doentes que não succumbem ao $1 .^{\circ}$ accidente, descobre-se que elles apresentavam ha mais ou menos tempo certos phenomenos dyspepticos e é bem provavel que Brinton acerte na verdadeira nota (tenha razão) quando diz que nunca observou caso algum no qual as dôres tenham faltado de modio absoluto! Sem nenhuma autoridade, eu direi que concordo "in totum" com esta affirmativa.

Mais adiante, referindo-se aos symptomas da ulcera em actividade estes mesmos autores assim dizem á pag. 345: “A ulcera em actividade accusa-se por tres symptomas fundamentaes que dominam o quadro clinico: a dôr, o vomito, a hematemese.

Sempre a dôr em $1 .^{\circ}$ logar!

No excellente livrinho sobre as ulceras digestivas escripto em collaboração pelos tres Pauls: Carnot, Mathieu e Harvier, este ultimo assim se refere á pag. 9: "Clinicamente, as dôres constituem o symptoma primordial da ulcera da pequena curvatura."

Mais adiante á pag. 23; tratando da ulcera do pyloro sem estenose clinicamente apreciavel, diz elle: "Esta ulcera, traduz-se por dôres d'intensidade variavel mas cujo momento de apparecimento tem um valor semiologico consideravel. Ellas sobrevêm, com effeito, entre 3 e 5 horas depois da refeição. São dôres tardias."

Sobre os doentes de ulcera do pyloro com estenose serrada, diz ainda Harvier á pag. 28: "Estes doentes soffrem de dôres muito vi- 
vas que apparecem logo após a ingestão dos alimentos e que augmentam com as contracções gastricas, desde que o estomago esteja cheio."

Em relação á ulcera do duodeno, diz ainda o mesmo autor á pag. 34 do citado livro: "A ulcera duodenal assemelha-se por muitos pontos á ulcera gastrica. Observamos a mesma evolução por paroxysmos de crises dolorosas separados por intervallos de calma ou de melhoria. E' geralmente, numa dessas crises dolorosas que o doente vem nos consultar Como na ulcera pylorica, a dôr é o signal mais importante."

Como na ulcera pylorica, diz o autor citado, o que significa para elle que em ambas estas variedades de ulcera a dôr é o signal mais importante!

Felix Ramond em seu bem lançado livro sobre molestias do estomago e do duodeno, edição de 1927, commentando a symptomatologia da ulcera pré pylorica, assim escreve á pag. 177: A dôr é o symptoma mais constante, pois que ella existe em $90 \%$ dos casos (Udaondo)

Descrevendo os meios empregados para se chegar ao diagnostico desta mesma ulcera, diz ainda Ramond, quando se refere ao exame radioscopico, pag. 181: "O symptoma mais importante é a fixidade da dôr provocada pela pressão, sob o controle do ecran." Ora, ahi está; a dôr quer expontanea, quer provocada é sempre o symptoma mais importante!

Referindo-se a ulcera pylorica, encontra-se isto, á pag. 185: "E' uma ulcera muito dolorosa com espasmo constante do esphincter e estenose rapida."

O grande endocrinologista italiano, Nicola Pende, em suas licções sobre "Ulcera gastrica e espasmophilia constitucional" publicadas na Gazeta das Clinicas e dos Hospitaes, nos mezes de Maio, Junho e Julho de 1926, diz, á pag. 4 do numero de Junho: "Toda a dôr constantemente fixa em um ponto da região gastrica, que insurge numa relação constante com a ingestão dos alimentos e se attenua quando o doente assume uma certa posição deve ser attribuida com todas as probabilidades a um processo do estomago de natureza ulcerativa e esta supposição adquire ainda mais valor se a dôr fôr acompanhada da presença de sangue no vomito."

O grande mestre italiano, com ser reservadissimo em todas as affirmativas que faz no decorrer das suas licções, não deixa de compartilhar da opinião da maioria dos autores, affirmando que só pelo estudo da dôr tem-se todas as probabilidades de se fazer o diagnostico de ulcera do estomago."

Passando da Europa para a America do Sul, posso citar o que diz Luiz Agote, em suas impeccaveis licções sobre "Ulceras gastricas e duodenaes na Republica Argentina" reunidas em volume publicado em 1916, á pag. 142: "Por su simple enunciado, el medico 
que ha visto ulcerosos, se plantea la sospecha de la existencia de la ulcera y en ciertos casos llega com ellos a precisar su diagnostico. En relación con el dolor, esta es la opinion corriente de los autores norte-americanos e inglezes.

W. J. Mayo lo dice bien claro en uno de sus ultimos trabajos y la experiencia diaria lo confirma. Muchos de ustedes lo han apreciado en los enfermos de nuestras salas y ya prevenidos no se les escapará en importancia para el diagnostico."

Mais adiante a pag. 143: "Los ulcerosos, como decimos, son enfermos perfectamente definidos. Bajo la influencia de la crisis dolorosa que roe sus entrañas, sus facciones expresan un dolor real, indiscutible, dolor violento, desesperante, referido sin vacilaciónes a un sitio determinado, siempre el mismo. No és necessario dirigirlo en el interrogatorio, el paciente encontrará facilmente la palabra apropriada a su sufrimiento y lo hará claramente sin vacilación alguna, describiendo todo lo que a el se refiere; las circunstancias bajo las quales se presenta; las causas que lo favorecem o alivian. Cuando el dolor ofrece particularidades bizarras, como por ejemplo, el hunger pain-dolor de hambre - son ellos los primeros en sorprender-se de esta curiosidad, tan distinta de lo que pudieran imaginar."

Ainda á pag. 158: "En la immensa mayoria de los casos, el dolor es el elemento predominante en el conjunto sintomático del ulceroso."

O eminente autor portenho corrobora francamente a minha asserção sobre a grande importancia do symptoma dôr e depois de consagrar-lhe tres alentadas licções, assim inicia a licção seguinte, tratando do syndromo acido-sensitivo, pag. 209: "Los tratados classicos a que ya nos hemos referido caracterzan el ulcus por tres sintomas principales: dolor, vomitos y hemorragia. Ya del primero nos hemos occupado con la extension exigida por su importancia, y aunque comprendemos estar muy lejos de haber agotado el tema bajo sus multiples fases, tenemos en nuestro haber un numero sufficiente de elementos para las necessidades de la clinica."

E' tão vasto e tão complexo, tão importante o problema da dôr, que o illustre professor argentino depois de dedicar-lhe tres minuciosas licções, declara estar muito longe de haver esgotado o assumpto! Nenhum outro symptoma, jámais requereu tanta attenção por parte dos tratadistas. E porque toda esta attenção? Por causa da sua indiscutivel importancia.

O proprio prof. Ovidio Pires de Campos que disse não estar de accôrdo commigo em collocar a dôr no logar que lhe compete na ordem symptomatologica das ulceras gastricas e duodenaes, já em tempos idos, considerou este symptoma como de capital importancia.

Em uma these sobre "Contribuição ao diagnostico topographico da ulcera simples", defendida pelo Dr. Messias Fonseca e approvada com distincção pela nossa Faculdade, em 1919, aquelle dis- 
tincto alumno do prof. Pires de Campos com quem trabalhou por mais de um anno na confecção de seu trabalho, diz o seguinte, á pag. 16: "A ulcera simples assestando-se na região da pequena curvatura do estomago, assume uma physionomia clinica tão caracteristica que é de se admirar que os autores classicos, a excepção de Mathieu, della se não tenham apercebido. O syndromo que della deriva foi magistral e inéditamente estudado pelo professor Maurice Loeper, da Faculdade de Medicina de Paris, de collaboração com Schulmann, em 1914. Por essa razão cognominou-se esse syndromo - Syndromo de Loeper. (*)

A homenagem, sobre ser, baixo todos os pontos de vista, cabivel e de justiça, tem para nós particular significativa: foi lembrada pelo presado mestre que nos inspirou este trabalho.

De facto, o prof. Dr. Ovidio Pires de Campos, em a sessão da Sociedade de Medicina e Cirurgia de S. Paulo, de 15 de Junho de 1927. realisada no Hospital de Misericordia de S. Paulo, em uma longa e documentada communicação a proposito de um interessante caso de ulcera da pequena curvatura do estomago, occorrido em o seu serviço da Santa Casa, em que o diagnostico se confirmou pela radioscopia e pela intervenção cirurgica, poz em destaque os diversos symptomas apresentados pelo doente, taes como a dôr (em $1 .^{\circ}$ logar!) e o vomito, com seus caracteres especiaes, a sialorrhéa, a bradycardia, o chimismo gastrico e o reflexo oculo-cardiaco, interpretando-os pela lesão dos filetes do pneumo-gastrico, como affirmára Loeper, a quem se deve a descripção magistral e precisa deste syndromo, que no seu modo de ver, deve ser denominado - syndromo de Loeper - do mesmo modo porque o syndromo das ulceras pyloricas é chamado syndromo de Reichmann."

$\mathrm{Eu}$ comprehendo perfeitamente o enthusiasmo do prof. Ovidio Pires de Campos por ter acertado tão bem um diagnostico de ulcera da pequena curvatura e dahi a sua ideia de se homenagear aquelle que pela sua magistral descripção o conduziu ao acerto do diagnostico, e pois que, no syndromo de Loeper, a dôr apparece em $1 .^{\circ}$ logar, como o symptoma mais importante, eu tambem bato palmas á proposta do prof. Pires de Campos.

A pag. 75, da these do Dr. Messias Fonseca, está escripto o seguinte, em relação á symptomatologia propria da ulcera do duodeno: "1. Dôr. O symptoma especifico da ulcera duodenal é a dôr." Esta affirmativa que vem mesmo a "talho de foice" por ser assim tão incisiva e categorica, não precisa de commentarios. Resta saber se ella foi escripta sem o consentimento e sem o conhecimento do prof. Pires de Campos. Não o creio, porque, em sua introducção, diz o autor da these: "Attendido em a nossa pretenção, procuramos desde logo dar o maximo do nosso esforço, para que o nosso trabalho não sahisse um aleijão. Com esse proposito ouvimos religiosamente,

(`) Na França, o syndromo é conhecido com o nome de Mathieu (Albert,) por ter sido este autor o primeiro a descrevel-o. 
durante mais de um anno, todas as magnificas prelecções e uteis ensinamentos que, sobre o assumpto, aquelle nosso mestre nos proporcionou."

E' de crêr-se, portanto, que o prof. Ovidio della tivesse tido conhecimento e tenha dado o seu consentimento para ser publicada. Uma outra hypothese que posso formular é a de que o illustre mestre tenha mudado de opinião daquella epoca para cá, mas, se assim succedeu, elle que me desculpe a franqueza, evoluiu para peior, no meu fraco modo de entender

Para terminar estas considerações direi que o Dr. Messias Fonseca apresenta em sua these, uma serie de 18 observações, a maior parte comprovadas pela operação ou pela necropsia, as unicas que têm valor real e algumas baseadas exclusivamente em dados clinicos.

Em todos os doentes que serviram para as observações, o Dr. Fonseca encontrou sempre a dôr como symptoma predominante, estando, assim, as suas observações perfeitamente de accôrdo com as de todos os autores que têm estudado o assumpto.

Finalisando, direi que um symptoma que tem sido denominado de: "o unico que tem grande valor (Moynihan) primordial (Harvier), predominante (Agóte), mais constante (Ramond), especifico (Fonseca) e mais importante (Harvier), no póde deixar de ser, para aquelles que assim o denominaram, o symptoma capital, o symptoma magno da affecção estudada.

Não quero com isto affirmar que não possa existir ulcera gastrica ou duodenal sem dôr Existe sem duvida, mas constituindo uma rarissima excepção: é a ulcera latente que só dá signal de si quando sobrevem uma hemorragia ou uma perfuração.

Si bem que nunca a tenha observado, em 18 annos de clinica e no estudo de uma grande quantidade de doentes examinados, acceito a possibilidade de sua existencia, como excepção. Mas, a ulcera latente, se não apresenta o prinicipal symptoma que é a dôr, tambem não apresenta os demais. O proprio doente não tem consciencia de que ella existe e por isso não toma nenhuma precaução, só se apercebendo da sua presença no decurso de uma hemorragia ou de uma perfuração. Quando qualquer uma destas complicações apparece sem que o individuo esteja dormindo ella é quasi sempre precedida de dôr mais ou menos intensa, tanto assim que já tem sido dado a eminentes clinicos e cirurgiões fazer o diagnostico, minutos ou horas antes de sobrevir a catastrophe. São, é verdade, casos raros.

$\mathrm{O}$ segundo ponto da minha communicação contestado pelo prof. Ovidio Pires de Campos e que desejo esclarecer é o que se refere á hematemese ou melhor á gastrorrhagia como signal pathognomonico da ulcera gastrica.

$\mathrm{Na}$ minha communicação affirmei que não dava grande valor ao exame do succo gastrico para fins de diagnostico. Neste particular só ligava attenção á presença de sangue em quantidade mais ou menos consideravel, pois julgava então que era um signal quasi pa- 
thognomonico de ulcera gastrica. Naturalmente, não dei ao termo todo o valor positivo de sua significação, pois de ha muito habitueime a considerar as coisas e factos da medicina como muito relativos.

$\mathrm{O}$ meu illustre collega, no emtanto, interpretou o termo em seu valor absoluto como se fosse uma lei impossivel de soffrer uma excepção; eu, pelo contrario, descreio do absolutismo em medicina.

Um symptoma qualquer, embora pathognomonico ou cognominado como tal, de qualquer molestia, póde apresentar-se em outras, verdade é que em caracter bem secundario. Não acredito em signal ou symptoma absolutamente pathognomonico de molestia alguma.

Em todo o caso, as minhas palavras não ficaram sem um éco, ou melhor ellas são um éco, do que dizem Lenoir e Agasse - Lafont no já citado XIII vol. do Nouveau Traité de Medicine, publicado sob a direcção dos profs. Roger, Widal e Teissier á pag. 547. Fallando da symptomatologia inicial da ulcera gastrica, dizem elles: "A's vezes, ella (a ulcera) é completamente latente. Bruscamente, em plena saude, sem perturbações gastricas anteriores, a ulcera se manifesta por um dos signaes pathognomonicos, hematemese ou perfuração."

Isto não significa, ao menos para mim, que outras molestias, locaes ou geraes não possam dar hematemese.

O prof. Pires de Campos citou a cirrhose atrophica do figado com a qual estou de pleno accordo, pois já confessei ter cahido em erro uma vez, quando em 1914, abri o ventre de um doente portador de hematemese e de outros symptomas que conduziram a mim e a mais dois distinctos collegas ao diagnostico de ulcera gastrica. A intervenção revelou tratar-se de uma cirrhose do figado com grande dilatação das veias do estomago e consequente hemorragia gastrica, talvez por hyperemia passiva da mucosa ou mesmo pela ruptura de alguma das veias.

No cancer, por um processo ulcerativo, destruindo as camadas que constituem a parede do estomago, póde dar se hemorragia abundante.

Nas gastrites, quer agudas, quer chronicas póde existir um gottejar continuo de sangue devido á hyperemia passiva da mucosa gastrica, produzindo hematemeses apreciaveis.

Segundo Nicola Pende, "nos individuos de idade avançada affectados de endoarterite syphilitica ou de simples arterio-esclerose, podem dar-se intensas gastrorrhagias, algumas vezes devidas a uma ulceração ou ruptura de aneurismas miliares, mas outras vezes sem que se verifiquem ulcerações da mucosa.

A hematemese pode dar-se ainda nas affecções das vias biliares e do appendice; existem, com effeito, casos de cholelithiase, acompanhados de angio-cholites chronicas com ictericia e sub-ictericia que dão logar á uma cholemia, a qual, provavelmente, por acção toxica sobre os capillares do estomago, póde causar pequenas ou grandes hemorragias repetidas, sem fallar que em casos de calculose da vesicula 
biliar póde sobrevir a perfuração desta no estomago, acompanhada de syndromo muito grave e de hemorragia abundante.

Hemorragias gastricas verificam-se ainda na chlorose, na leucemia, na anemia perniciosa e em diversos syndromos hemorragicos como a hemophilia e a purpura."

Segundo Pende, "póde ainda haver estravasamento de sangue no estomago, nas hemorragias cerebraes, nas crises gastricas da tabes, na neurasthenia e na hysteria."

Não devem ser esquecidos os processos pulmonares, pharyngeanos e mesmo os nasaes que podem dar hemorragia, sendo o sangue deglutido e depois expellido sob a fórma de hematemese.

Mas, se a hematemese póde apparecer em todas essas molestias que acabo de citar, nem por isso ella perde o seu valor no diagnostico de uma ulcera quando appareça sangue em quantidade apreciavel.

Ella vem sempre acompanhada de outros symptomas, que orientam facilmente o clinico sobre a sua causa verdadeira.

Do exposto, vê-se que continuo a affirmar poder a presença de sangue no succo gastrico ser um signal pathognomonico de ulcera gastrica.

O $3 .^{\circ}$ ponto da minha communicação que necesita de ser esclarecido é o que se refere a estase nas ulceras do duodeno.

Fallando da radioscopia como excellente meio de diagnostico, nas ulceras do duodeno, disse que, geralmente, quando existe uma ulcera daquella parte do intestino, o estomago apresenta, ao receber a refeição opaca, fortes contracções peristalticas, que impellem a refeição por grandes golfadas através de um pyloro mais aberto do que normal mas que essas contracções, nos meus casos, cediam, em pouco tempo, o logar a outras cada vez menos activas, de forma tal que o estomago depois de algum tempo cahia em hypotonia e mesmo em atonia, deixando, por isso, de se esvasiar completamente no prazo normal e dando-se assim a estase, isto é, persistindo uma parte da refeição opaca, depois de seis horas.

O prof. Pires de Campos oppoz formal contradicta á minha asserção e procurou mesmo explicar o mecanismo pelo qual o estomago se esvasia mais rapidamente do que o normal, em casos de ulcera do duodeno.

Não acreditou o meu illustre collega, cuja opinião estou acostumado a acatar com respeito, nas radiographias que apresentei, demonstrando a estase em doentes portadores de ulcera do duodeno, se bem que o diagnostico tivesse sido confirmado pela intervenção cirurgica e as peças anatomo-pathologicas estivessem presentes para ser examinadas.

Tenho, portanto, que recorrer, em primeiro logar, á opinião dos autores extrangeiros, infinitamente mais valiosa do que a minha e em segundo logar á opinião dos radiologistas desta Capital. 
Antes de mais nada, estabeleço esta premissa, que uma ulcera recente do duodeno frequentemente apresenta os caracteres radioscopicos commummente descriptos, isto é, abertura do pyloro, fortes contracções peristalticas do estomago, esvasiamento rapido deste orgam, em menos tempo do que o exigido normalmente - o chamado syndromo de Barclay, ou seja a triade dos hyper, dos autores americanos - hypertonia, hyperperistaltismo e hypersecreção.

Mas, a ulcera duodenal antiga, chronica, tem tendencia a formar tecido fibroso na sua parte peripherica, embora o seu centro continue em actividade.

Ora, este tecido fibroso, verdadeiro tecido cicatricial tem grande tendencia para retrahir-se repuxando as mucosas do intestino e do estomago que assim formam verdadeiras pregas salientes para a luz do orgam e irradiando-se da ulcera, como um centro.

E' o que os autores americanos chamam de corona radiata.

Esta retracção da parte peripherica da ulcera e o consequente pregueamento da mucosa, que della resulta, dão, como é muito logico de se suppor, uma estenose com retardamento na passagem da refeição opaca. A principio, o estomago lucta efficazmente para franquear a barreira duodenal, mas, depois de algum tempo, cansado, extenuado, elle deixa-se vencer e cáe em atonia da qual resulta a estase.

Os casos por mim operados, são todos casos chronicos, cujos males, datam, no minimo, de dois annos e por conseguinte com um pouco de direito a uma estenose e consequente estase de retenção.

Em meu favor posso citar a opinião dos autores americanos Carman e Miller, radiologistas da Clinica dos irmãos Mayo, que dizem o seguinte, a pag. 408 do seu livro sobre: "Diagnostico roentgenologico do apparelho digestivo", publicado em 1917:

"Deve ser lembrado que a hyper-motilidade não é peculiar a ulcera duodenal, sendo tambem uma consequencia commum do cancer gastrico, da acchylia e das diarrhéas. Se estas causas forem excluidas, como geralmente podem ser tomando-se em consideração os factos clinicos e roentgenologicos mais salientes, uma hypermotilidade pronunciada falla muito a favor da possibilidade da existencia de uma ulcera duodenal sem obstrucção.

Por outro lado, dizem elles, mais de um quarto das ulceras são sufficientemente obstructivas, para produzir no estomago, uma retenção, depois de seis horas.

Carman e Miller admittem que, apenas um pouco mais de um quarto das ulceras do duodeno provocam estenose e consequente estase gastrica, porque nos Estados Unidos qualquer doente que se queixa do estomago é logo radiographado, de modo que tanto o diagnostico como a intervenção cirurgica são bastante precoces em casos de ulcera. E' por isso que a maioria das ulceras examinadas por aquelles eminentes radiologistas é surprehendida, ainda no pe- 
riodo inicial, não apresentando, por conseguinte, nem estenose e nem estase.

O mesmo não se passa entre nós, segundo a minha experiencia.

A maior parte dos doentes de ulceras do estomago e do duodeno que tenho operado, tem-me procurado com o seu mal em estado já tão avançado e tão caracterisado que a radiographia apenas confirma o diagnostico e localisa topographicamente a ulcera e se esta é situada no pyloro ou no duodeno já houve tempo sufficiente para a formação de uma estenose.

Julgo que, da mesma forma, passam-se as coisas em França, pois no seu livro sobre "Radiodiagnostico das molestias do apparelho digestivo", edição de 1925, tratando da ulcera do duodeno, diz Ledoux-Lebard, á pag. 238: "A hypermotricidade é a consequencia da hypertonia e do hyperperistaltismo (signal da triade dos hyper, do autores americanos). Ella traduz-se por uma evacuação anormalmente rapida do conteúdo gastrico, effectuando-se na metade ou no terço do tempo habitual e frequentemente em menos de uma hora. (Esta constatação, não tem valor, bem entendido, senão com uma verdadeira refeição opaca, o leite simples não permittindo a esse ponto de vista conclusão alguma).

Mas, diz ainda Ledoux-Lebard, a maior parte das vezes, esta evacuação precipitada é incompleta; persiste um residuo gastrico, fraco é verdade, para o qual se observa um atrazo accentuado na evacuação.

Da mesma opinião, é o grande radiologista francez Henri Beclére, quando declara no seu livro sobre "Estudos medico-radio-cirurgicos sobre o duodeno" escripto em collaboração com Pierre Duval e Jean Charles Roux, á pag. 219, da 1. a edição, publicada em 1924: "Evacuação do estomago. O estomago, no decurso da ulcera do duodeno, apresenta babitualmente uma hypermotibilidade inicial, com retenção paradoxal."

E' como se vê, a mesma opinião de Ledoux-Lebard, expressada em forma mais concisa.

Hypermotilidade no inicio, com hypomotilidade ou mesmo atonia subsequente, dando em resultado uma retenção. Tal qual, como tenho observado em muitos dos meus casos inclusive aquelles que aqui não foram apresentados.

E' tão verdadeiro e tão constante este signal da estase nas ulceras duodenaes que elle tem servido para estabelecer o diagnostico entre estas ulceras e as da pequena curvatura, segundo diz Ledoux-Lebard, á pags. 198 e 199, do seu já citado livro, tratando da ulcera da pequena curvatura: "Como consequencia desta hyperactividade, a evacuação do estomago é geralmente accelerada de um modo consideravel, pelo menos no inicio. Ella pode, em seguida, diminuir ao ponto de permanecer um residuo gastrico apreciavel da refeição opaca, até a 5.a hora. Todavia, esta ultima constatação é mais frequente 
ainda na ulcera do duodeno do que na ulcera gastrica propriamente dita e quer se ver nesse signal um ponto de differenciação radiologica entre as duas affecções.

Dentre os radiologistas desta Capital, eu peço licença para citar em 1. ${ }^{\circ}$ logar a valiosa opinião do dr. Octavio de Carvalho, pois que, já na sessão de 1 de Agosto, elle manifestou-se favoravel a minha affirmativa, tendo declarado haver encontrado estase em casos de ulcera do duodeno por elle diagnosticados.

Os drs. prof. Raphael de Barros, Cassio Villaça, Nagib Scaff e Francisco Finocchiaro, já me têm enviado mais de um relatorio radiologico nos quaes mencionam a passagem lenta da refeição opaca e consequente estase e no entretanto concluem pela existencia de uma ulcera do duodeno.

Alguns destes casos operados por mim confirmaram o diagnostico radiologico, mas mesmo que uma intervenção não fosse feita para confirmal-o, isto prova que os nossos illustre radiologistas admittem a existencia de uma ulcera do duodeno com estase.

Parece-me não haver mais duvida alguma sobre este ponto.

Finalmente, uma outra parte da minha communicação que foi contestada, esta, só pelo dr. Octavio de Carvalho, foi a referente á rectitude da pequena curvatura, phenomeno apreciavel em certas radiographias, especialmente naquellas de doentes portadores de estase. E' um signal de facil observação, commumente descripto em connexão com a existencia de uma ulcera da pequena curvatura, mas de difficil explicação, não estando ainda os radiologistas perfeitamente de accôrdo sobre o mecanismo de sua producção.

Mostrei aos meus collegas, tres chapas nas quaes disse observar se a rectitude da pequena curvatura.

O dr. Octavio de Carvalho affirmou na occasião que o que eu havia mostrado não era caracteristico da rectitude da pequena curvatura e que elle demonstraria o que interpreta como sendo o signal typico.

Não sendo um radiologista, mas unicamente um curioso com muito boa vontade de aprender eu esperei que o meu illustre collega me demonstrasse o erro em que eu havia incorrido, para corrigir-me.

Infelizmente, não tive o prazer de assistir áquella demonstração, por isso, ao voltar para casa, fui folhear o relatorio do $29 .^{\circ}$ Congresso francez de cirurgia, publicado em 1920, onde eu tive pela primeira vez, conhecimento da existencia de semelhante signal e lá vi, á pag. 100, os eschemas apresentados por Pierre Duval e Henri Beclére como typicos da rectitude da pequena curvatura.

Observando-os attentamente, vê-se que tres delles estão de accôrdo com as tres radiographias que apresentei e cujas copias aqui tenho para serem confrontadas.

Dess'arte, se estou errado, quer me parecer que os dois illustres mestres francezes tambem o estão, porquanto apenas transmitto o que delles aprendi. 
Meus senhores, eu não tenho a pretenção de querer convencer o prof. Pires de Campos e o dr. Octavio de Carvalho de que elles estão enganados no que affirmaram. Não conheço os detalhes dos casos por elles estudados; por isso, creio que as suas affirmativas foram feitas com convicção, baseadas na experiencia de outros e testemunhadas por experiencia propria. Todavia, não posso concordar com o que elles affirmaram, em face dos meus casos, porquanto a minha experiencia é bem differente e as palavras que acabo de proferir, têm unicamente, por fim, demonstrar-vos que o que eu affirmei, foi o que eu verifiquei e que pude documentar.

Essa verifcação e essa documentação concordam, como vedes pelo exposto, com o que tem sido feito de melhor no assumpto, especialmente por autores extrangeiros.

Reconheço quão insufficiente e quão cheio de falhas foi o meu trabalho, mas dadas as difficuldades que encontrei, podeis crer que elle representa um grande esforço e por isso, espero merecer a benevolencia das vossas desculpas.

Resta-me agora agradecer-vos por terdes me ouvido com tanta attenção. Agradeço, particularmente, ao prof. Ovidio Pires de Campos e ao dr. Octavio de Carvalho por terem com a sua discussão, me proporcionado a opportunidade de melhor esclarecer o assumpto que por falta de tempo e por deferencia ao illustre prof. Laroche, foi tratado de modo superficial na sessão passada.

Espero que esta minha communicação tenha um unico mérito, qual seja o de despertar a attenção dos estudiosos, para que o nosso progresso, neste assumpto, possa andar "pari-passu" com o progresso realisado no extrangeiro e do qual ainda nos achamos bem distantes.

Nota: Os gryphos são meus.

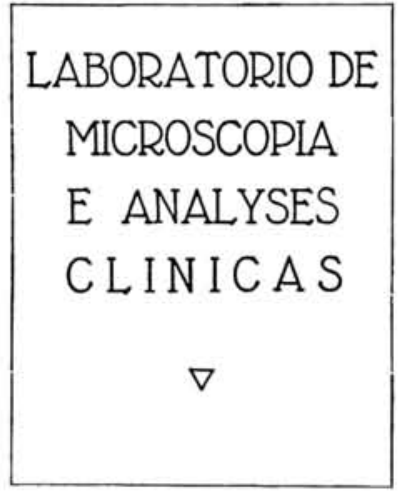

\section{Dr. Altino Antunes}

RUA DO CARMO N. 11 TELEPHONE 2463 (CENTRAL) SÃO PAULO 


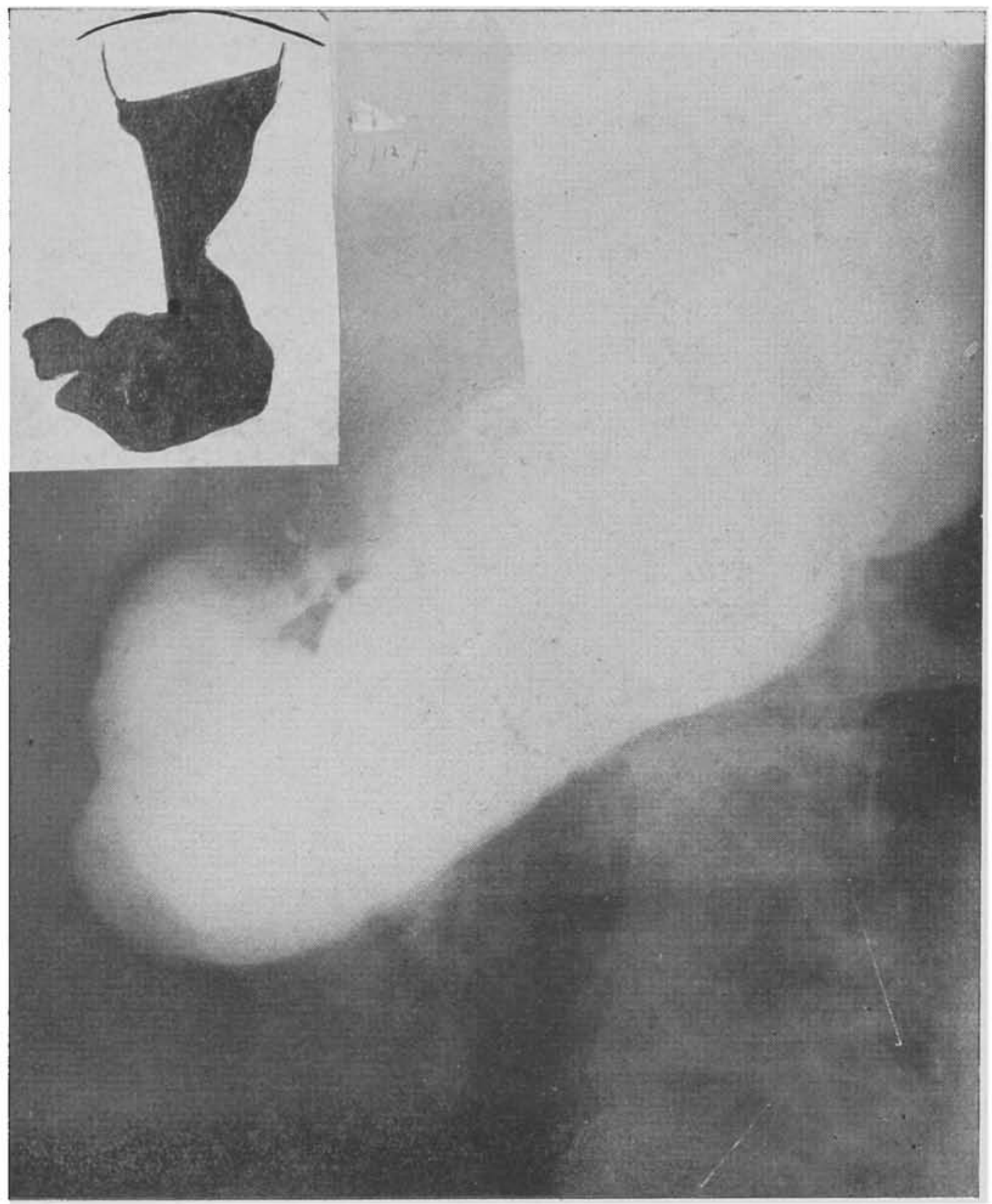

Radiographia mostrando a RECTITUdE DA PEQUENA CURVATURA. (CASO do aUtOr).

EM CIMA, Á ESQUERDA, NO PEQUENo QUADRO, ESCHEMA N." 23 apresentado por Pierre Duval e Henri Béclere, cono TYPICO DA RECTITUDE DA PEQUENA CURVATURA. 



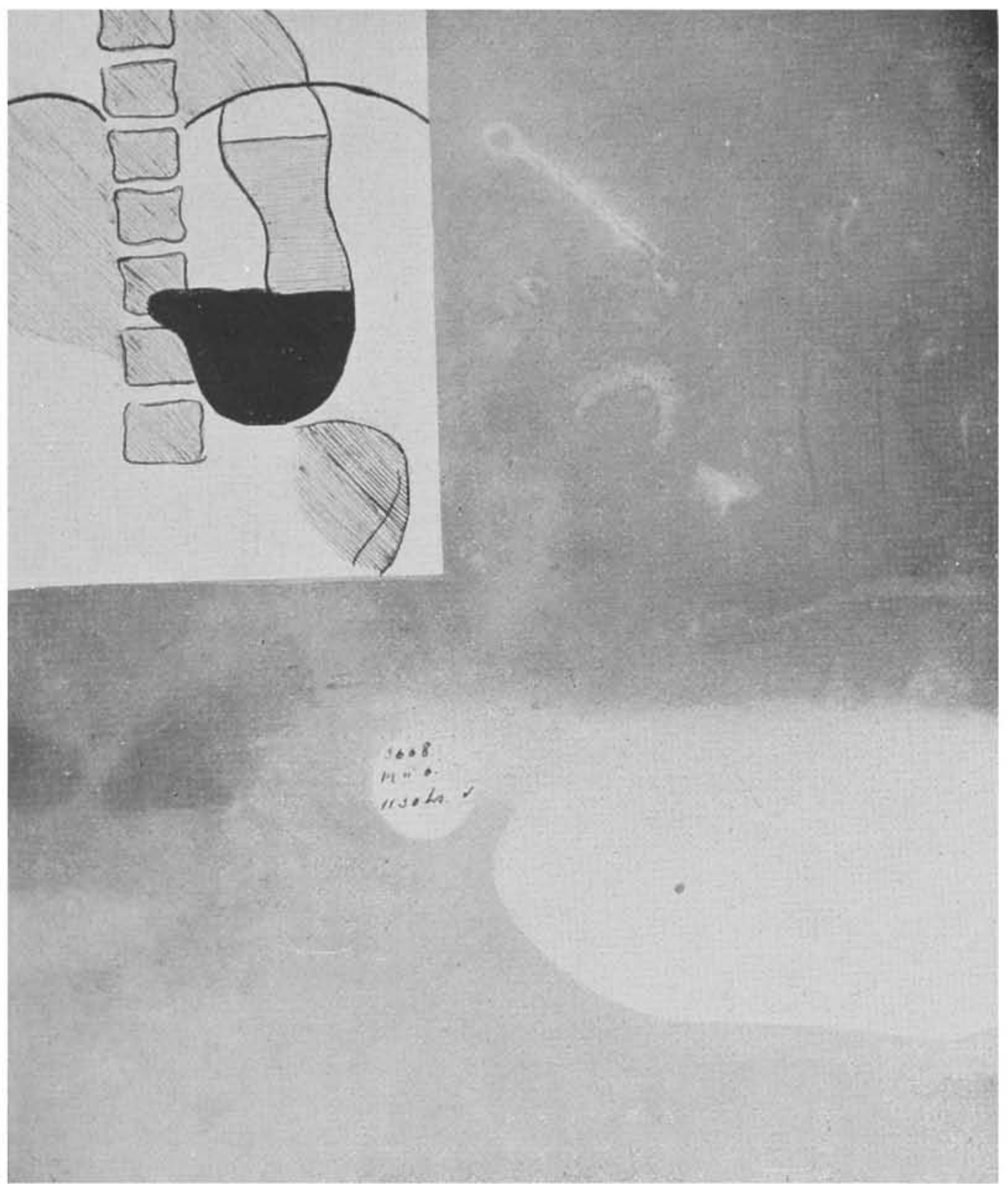

RADIOGRAPHIA MOSTRANDO RECTITUDE DA PEQUENA CURVAtURA, ATÉ O PYloro. (CASO do AUTOR).

Em cima á esquerda, eschema n. 24 de Pierre Duval e Henri Beclere. Na radiographia do autor vế-Se sóMENTE A PORÇÃO HORIZONTAL DO ESTOMAGO. 



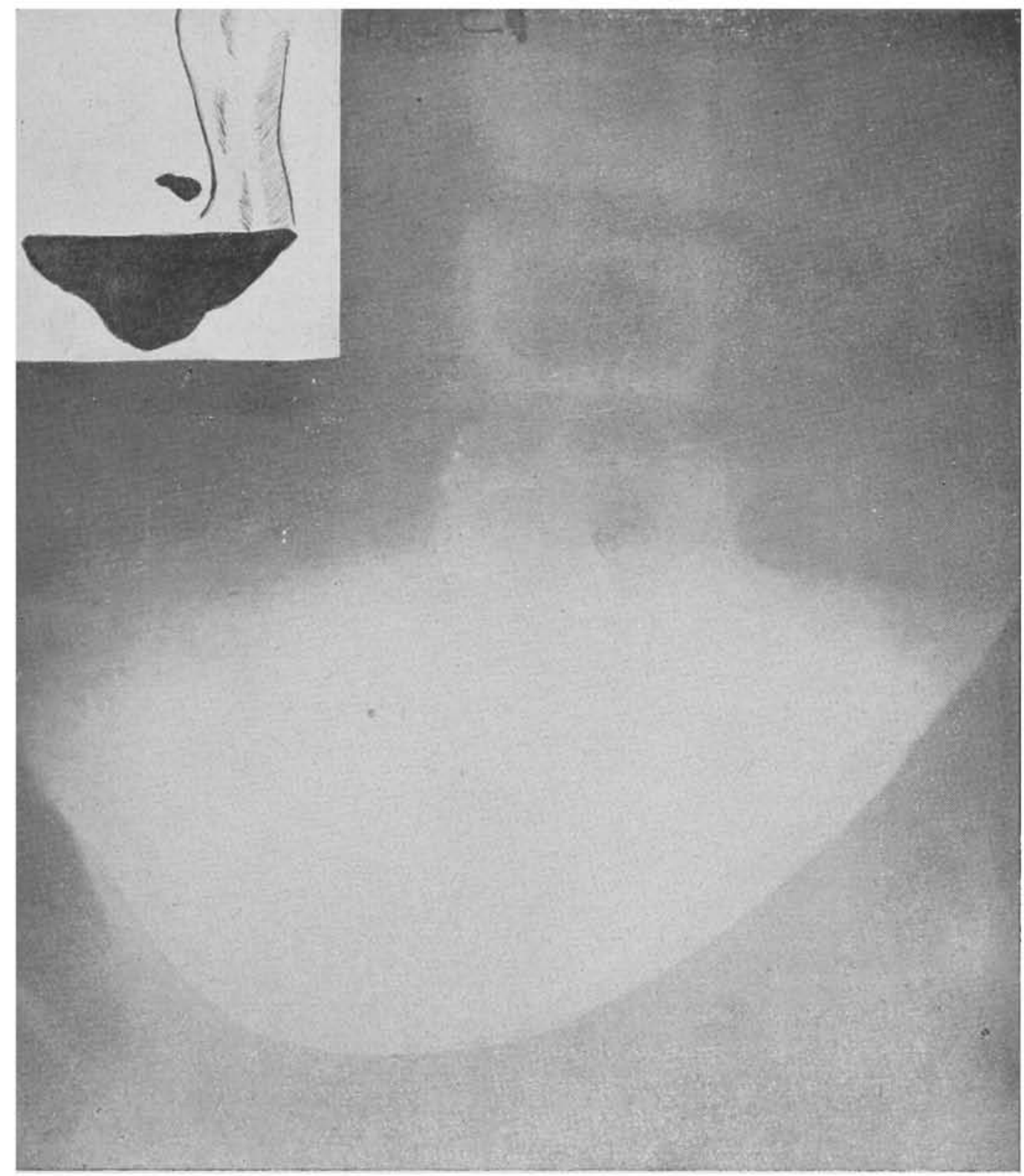

RADIOGRAPHII MOSTRANDO UMA FÓRMA MUITO ACCENTUADA DE RECTITUde DA PEQUena CURVATURA. (CASO DO AUTOR). Em cima, á esquerda, eschema n. ${ }^{\circ} 25$ de Pierre Duval e Henri Beclere. 